\title{
The Research of Effective Teaching in Colleges Based on the Theory of Social Facilitation and Social Loafing
}

\author{
Haixia Li, Shimeng Ma \\ Department of economics and management, Shijiazhuang University, Shijiazhuang, Hebei Province, China \\ lihaixia133@163.com, dongfeng624@sohu.com
}

\begin{abstract}
Now the teaching in college, many negative phenomena affect the effectiveness of teaching, and can not be fundamentally solved for so long a time. In this paper, using the theory of social facilitation and social loafing ,through the understanding of effective teaching to analyze the existing problems in the current class teaching in colleges and universities, the problems of college students, school, family and social are analyzed, and finally put forward solutions and countermeasures, so as to ensure the effectiveness of college teaching.

Index Terms - Social facilitation and social loafing, Effective teaching, Problems, Solutions
\end{abstract}

\section{Introduction of related theory}

Social facilitation refers to the phenomenon of the increased behavior efficiency caused by the presence of others or others activities when the individual is completing an activity. When individuals engage in activities, whether existing the audience, the number of audience and the audience performance have obvious influence on their activities. When the individual activities are not skilled or self demands are too high, they will produce social inhibition, and reduce their efficiency; on the other hand, when the activity they engaged in is their strengths or self requirements are for normal, the activity efficiency will be strengthened.

Social loafing refers to when a person is participating in collective activity, but cannot be evaluated separately, the degree of individual effort should be smaller more often than completing the task alone. The degree of individual efforts in the group task mainly depends on two factors: one is that the degree of individual importance or the necessity of his efforts to complete the task on the success of the group. Individual initiative and motivation in groups are not stronger than working alone. And the more the number of group, the more the individual motivation may be reduced. The other is that the success value of group the individual think. In group activities, individual effort is usually anonymous, when the individual sense of responsibility is reducing, that their performance will not be found, or without the need to take responsibility for their actions, they will be relaxed in the group. Therefore, the larger group is, the higher the degree of social loafing will be.

Constructing and the creating of an effective class teaching means to prevent, abandon or cancel the drawbacks of the classroom inefficient furthest, rather than changing the class form and appearance. The true effective class teaching is the subversion of the traditional teaching, thoroughly lets students be the master, takes the textbook knowledge as the amusement park, the teacher take the students surfing in the knowledge, the students will study actively, accept the knowledge in happiness.

Efficient teaching is based on the solid teaching content. The teaching content is the carrier of class teaching to promote the development of students. Efficient class teaching is not the more the teaching content the much better, not the more "difficult" the better, but based on the understanding of students' actual development level and characteristics, to determine a reasonable teaching content. Therefore, in class teachers should ensure plenty of practice to implement the teaching focus to enable students to master basic knowledge, basic skills development. The students in class can use independent learning, cooperative learning, inquiry learning and so on, let the "passive learning" to "active learning", change "you want me to learn " to "I want to learn". Give full play to the initiative, and creative of students as the premise the initiative, guide them take autonomous learning, cooperative learning and inquiry learning in the democratic, loose, harmonious atmosphere in order to achieve the effective class teaching effect.

Performance management is a kind of gradually positioning method through identifying, measuring and conveying the information of performance level of the related staff, to achieve the organization goals, which is a full circulation system made up by performance plan, performance counseling, performance evaluation, performance communication and so on. Performance management originated in enterprise management, it has experienced a development process from performance evaluation to performance management, since the 90's of last century, performance management has become one of the functions of human resource management, which is an important modern management tool widely accepted is. The ultimate purpose of performance management is to achieve double promotion between organizations and individuals. In recent years, college teachers in China have taken performance evaluation based on the organization construction and the development of colleges. There are many problems in evaluation of college teachers compared to performance management concept.

\section{The current problems existing in the college teaching}

Through the teaching experience of many years, I summed up the problem behaviors of college students mainly have the following several kinds: first, talking in class, truant, 
playing mobile phone, the three problems are the most prominent; the second is sleeping, listening to music, reading other books, late-coming or early-going, eating snacks; again, from the nature of curriculum, the problems of optional class are the most serious, the rate of truancy reached $26 \%$, even to the attending students most did not study. In the results of survey to the students reflected that, nearly $90 \%$ of students could not understand their knowledge, they thought that their knowledge was too little, about $50 \%$ of students lacked the courage to stand up to answer the questions, and did not dare to express their views in class.

\section{The reasons of problems}

Given these problems, what are the main factors causing these problems? We must take reason analysis clearly, summed up the following aspects:

\section{A. The college students themselves}

1) The lack of learning motivation. College students come from the high tension of learning career to relatively free environment in colleges, without the pressure of entering a higher school, no parents urged and the lack of clear goals, which make most students have emotional burnout on learning, so all kinds of negative performance are also producing. The survey found that about $90 \%$ of the students didn't know much about their knowledge, according to the social facilitation theory, when students are not familiar with the professional knowledge, the efficiency of their learning will be reduced and thus they will lose the interest of study.

For college students, professional skills and professional theoretical knowledge are essential, college is the place of learning knowledge, and our main purpose of going to college is to profound professional knowledge, to actively expand their reserves of knowledge. And have a look at the present college students, class attendance can be said to be very low, and there are few students in the class to study! According to the survey, $86 \%$ of the people believe that college students should have professional foundation, $77 \%$ of the people think that college students should have the extensive and profound knowledge and $75 \%$ of the people think that college students should have the concept of life-long learning, thus we can know social demand is very high to the students' knowledge , our knowledge includes not only the professional knowledge, but also including other humanities knowledge, knowledge of nature reserves, because only the knowledge reserve is enough can we improve our own accomplishment.

2) The self-restraint ability are weakened. At this stage, the society has less and less expectations to college students, as to the requirements of them, so the students also have lower and lower requirements to themselves. And the class is the collective class, in the group, according to social loafing theory, students will think that there are other students answering the teachers' questions, they need not answer the questions, and the teacher can not hear him, thus lead to reduce the requirements to themselves.

3) Tway of self-learning. In college there is no the constraint and pressure, the students finally free from pressure, they are relaxed, leading to no target to pursuit.

\section{B. The factors of school}

1) Professional level of some teachers is not high. Knowledge of some teachers can not update their knowledge timely, the teaching content is obsolete and lacks of keeping pace with the times, the teaching styles and methods of some other teachers are not flexible and force the knowledge to students, making students lose interest. In a questionnaire survey on "Which administrative department is for the evaluation of teachers in your school?" among the answers choose the registry for $33 \%$, choose the research department accounted for $19 \%$, choose personnel accounted for $6 \%$, the choice of not clear accounted for $46 \%$. The findings provide information in two areas: one is the most teachers are receiving appraisal, but they are not clear the department of teacher evaluation; the other is many sectors assess on teachers, such as the office of academic affairs, department of scientific research, personnel, etc.

2) The class management is not strict. College students are not the primary and secondary school students, they can't be managed like before, so the management to them is easier, so the class is unattractive. There are disciplinary measures to truant students, but no a corresponding management and control method to those who don't listen to the lessens seriously. The evaluation of teachers are in various forms, such as the office of academic affairs take teaching evaluation for teachers at the end of each semester, scientific research department organized to the teacher's scientific research project and thesis evaluation each year, personnel department, propaganda department organized to the advanced teacher selection at the end of each year, etc. The content of the evaluation is different, the evaluation subjects are different. So, there are the diversities of evaluation standard and evaluation results, but there are no uniform results as the overall status of college human resources or the comprehensive evaluation results of college teachers.

\section{The factors of family and society}

1) The ways of family education. Many college students are the only child in their family, even if not, now that the children are also be spoiled, so they have a good sense of self consciousness, in the class they also persist in their old ways.

Not harmonious family relations will have a bad impact on the family members of the perception, emotion, emotion, personality and ability, especially for minors deeper influence. This is because the cognitive, emotional, personality of minors are not mature and perfect, not perfect family relationships lead to apathy, streak, lonely, and even self sealing, poor self-confidence, interpersonal and social activities method are simple, they do not know what to do, sometimes they refuse to communication, social phobia, be afraid of hurt. But in school they are impossible not to communicate with people, especially after entering the college, they are away from family and friends and familiar environment, interpersonal relationship and meet the professional need to start from scratch. If they can not adjust and take no effective intervention in the initial stage, there will be forced, anxiety, paranoia, depression, hostility, phobic anxiety, and make the interpersonal relationships in a state of 
tension, the scope of social is narrow .

2) The negative effects of social environment. First of all, the employment pressure forced them to leave the class for the postgraduate entrance examination, verification or employment; secondly, higher tuition fees and living expenses lead to a part of students have part-time job during the school, so truancy is inevitable; third, the society identity of college students is declining, so that a part of students think there is no use to go to college. It will make more and more problems in college teaching, and more and more serious.

\section{Solutions}

Reasons on the above analysis of college students performance, students need is a lively and fulfilling class teaching, in according to the effective teaching standards, to establish effective teaching, we must according to the needs of the class subject—students to find effective solutions, the followings are the solutions from the students, teachers, families and society.

\section{A. Stimulating students' learning motivation and strengthening their self-control ability}

Learning motivation is internal motivation and external motivation to promote students' learning, we mainly refers to the internal motivation of students. we found that student's learning motivation is related to his ideal level, the more the ideal is, the greater the student's power is, so that it will be more and more familiar with their knowledge, so as to improve and enthusiasm to class, the problems also will be reduced accordingly. At the same time establishing a proper evaluation standard, let the students feel that what they give away can be assessed, for example, in accordance with the class performance and attendance to give usual performance etc.

1) Accumulating knowledge and increasing the stock of knowledge. College is a bridge connecting the society, is the exercise place before the students entering the society, so in order to be adapt to the society better, college students should learn, accumulate a lot of knowledge. college is a good place for us to study, college students should go to the library to enrich themselves, to improve their quality, perfect themselves, to make up for the defects and deficiencies of themselves. Because we have sufficient free time to learn all aspects of knowledge in the college period, which is very important to the future work and social communication.

2) Participating in social practice actively. Social practice is a good exercise way in the college period. It can improve our comprehensive quality and practical ability, and it can train our ability to deal with problems early, and take part in social practice activities can increase our communication, know more friends, improve their communicative competence, and it is also good to train career responsibility and leadership, strengthen the team spirit, and enhance professional awareness.

3) Improving their psychological quality. Any successful people have a good psychological quality, so when they encounter problems, they do not shrink or be hit down, they can be in contrast to the difficulties, and in the face of adversity to make progress, to find a solution, to overcome difficulties and success. Therefore, they should improve the psychological quality. Psychological quality of contemporary college students is a gradual increase in the process of learning, not a short duration of time. The so-called constant dripping wears away a stone, college students need to overcome the psychological setback little by little. In daily life, college students have to adhere to exercise firm and indomitable personality, learn to have a good relationship with the students around, to know how to be considerate of others. They need a positive attitude to eliminate the obstacles to success, to reach the shore of victory.

\section{B. Improving their own quality of teachers}

Fully prepare for each class, constantly enrich himself in order to have a good attitude to take each class, and use different teaching methods, allow students to participate in teaching activities in the maximum. Be the audience of the students, encourage and guide students to explore learning, make the class interesting, meaningful, and help them find confidence in learning, so as to improve learning efficiency. Performance management is a kind of modern management tools, and any management tool must be made by the competent departments, also only in this way, can make the management work to be developed effectively and orderly. So, performance evaluation to college teachers needs to carry out under the premise of making it clear the specific departments.

The teachers should affect students' concept of time, help students develop a schedule, use reflection time, let the students learn to manage the classroom 50 minutes, allow it to produce the greatest benefits. Teachers must set up the concepts that the students can learn, every student can learn , to help students develop a self-learning program, answer the students' questions. For the questions most of the students can solve through self-study need not teaching, those students can not solve should teach seriously. Maximize the feedback learning situation of students, and create a harmonious and efficient classroom atmosphere.

Teachers should often listen to students' suggestions in the learning, and adjust their teaching strategies timely, respect students learning way to the utmost. Teachers should respect the results of the student labor, don't sarcastic answer the students' mistakes. Teachers should look at students with a sincere eyes, kindly teaching students, guide the students trust attitude. The initiative to create a democratic, loose, harmonious atmosphere in the hands of teachers, teachers must take the initiative to undertake the responsibility of improving the relationship between teachers and students.

\section{Change the views and attitudes of society and family on college students}

College counselors should maintain frequent communication with the students' parents to communicate students' situation in college, the parents should make themselves examples, cooperate with the college to take self education on students. To society, we should also have an encouraging attitude for college students, but not just the negative criticism and pressure on them. College, family and 
society should be cooperative, helping students to set goals, strengthen confidence, to ensure good performance in class.

The growth of college students, fundamentally speaking, is rooted in the social environment, and also is rooted in the social life, the good social environment in China is conducive to the growth of college students. Only on the basis of equality and comfortable atmosphere, students can be pleasure to learn, and achieve good results. In order to improve the learning enthusiasm of the students, cultivate the creativity of students, teachers should strive to create a democratic, loose, harmonious teaching atmosphere, which is conducive to encourage students' independent consciousness, creative thinking of the students, to inspire students' imagination, collision and exchange for different points of view.

Students are the future of the motherland, the whole society should unite, so as to enable them to the national service better, to make our country more powerful.

\section{References}

[1] Xiaoli Ni. Social psychology. Xi'an: Xi'an Jiao Tong University Press, 2007, pp251-257

[2] Limin Yao, Xia Cao, Shuzhen Huang. The investigation and analysis of the teachers' class effective teaching. Chinese University Teaching, 2011 (10), pp77-81

[3] Hongshen Liu, Jianxin Li. Research on the effectiveness of the model of interaction between teachers and students in college class teaching. Chinese Power Education.2011 (1), pp52-53

[4] Guibo Du. Research on the effectiveness of college journalism class Harbin: Harbin Normal University, 2011, pp45-47

[5] Xiaoqing Yang, Jie Li. Analysis of strategy on the effective teaching of college teachers (EB/OL). China Paper Net, July $17^{\text {th }}, 2012$ 